\title{
INOVAÇÕES TECNOLÓGICAS NA CADEIA PRODUTIVA TÊXTIL: ANÁLISE E ESTUDO DE CASO EM INDÚSTRIA NO NORDESTE DO BRASIL
}

\section{TECHNOLOGICAL INNOVATIONS OF THE TEXTILE PRODUCTIVE CHAIN: ANALYSIS AND CASE STUDY IN INDUSTRY IN NORTHEAST OF BRAZIL}

\author{
Miguel O. B. C. Melo \\ Universidade Federal da Paraíba-UFPB \\ Cidade Universitária - CEP: 58051-970 - João Pessoa-PB \\ mobcmelo@terra.com.br \\ Guilherme A. Cavalcanti, Dr. \\ Universidade Federal da Paraíba-UFPB \\ Helen S. Gonçalves \\ Programa de Pós-graduação em Engenharia de Produção-UFPB \\ Sibele T. V. G. Duarte \\ Programa de Pós-graduação em Engenharia de Produção-UFPB
}

RESUMO

Este trabalho tem por objetivo descrever as principais inovações tecnológicas que vêm ocorrendo no setor de fiação da cadeia produtiva da indústria têxtil no Nordeste do Brasil, tomando-se como referência um estudo de caso de uma empresa da região. São descritos o estado da arte e o histórico da evolução da indústria têxtil no Brasil e analisa-se, com base num referencial teórico da cadeia produtiva têxtil, a empresa. Também é apresentada uma visão geral do desenvolvimento tecnológico do setor, o cenário atual e o melhoramento dos seus processos produtivos. Por fim são descritas algumas razões e necessidades que levaram as empresas a se modernizarem utilizando a inovação tecnológica para melhorar a sua produtividade e qualidade dos seus sistemas de produção.

Palavras-chave: Sistemas de Produção Regional. Inovação Tecnológica. Indústria Têxtil.

\begin{abstract}
The purpose of this work is to describe the main technological innovations that have been occurring in spinning sector of the textile productive chain in the industry in Brazil's Northeast. It is accomplished a case study in a textile company of the region. Based in a theoretical referential of the textile productive chain, the historical of the evolution of the textile industry in Brazil are analyzed. Overviews on the technological development of the sector and the improvement of their productive processes are introduced. The reasons and needs which enabled the companies to modernize using the technological innovation to improve your productivity and quality of their production systems are described.
\end{abstract}

Keywords: Regional Production Systems. Technological Innovation. Textile Productive Chain. 


\section{INTRODUÇÃO}

Nas últimas décadas os diversos setores da economia brasileira passaram por mudanças profundas, seja em função de mudanças conjunturais, ou por inovações tecnológicas, que têm alterado funções e processos, e criando maquinários cada vez mais velozes (SICSU, 2001a).

No setor têxtil, particularmente, o efeito causado pelas mudanças tem levado a mudanças tanto no comportamento da empresa, quanto em sua participação no mercado. Daí a necessidade de se estudar as principais inovações tecnológicas, em termos de melhorias de equipamentos, que vêm ocorrendo nos últimos anos, e como isso está se refletindo nos resultados do setor (PIO, 2000).

O objetivo deste trabalho é descrever as principais inovações tecnológicas que vêm ocorrendo na cadeia produtiva da indústria têxtil no Nordeste do Brasil, tomando-se como referência de estudo de caso numa indústria em uma empresa da cidade de Campina GrandePB. São apresentados o estado da arte e o histórico da evolução da indústria têxtil no Mundo e no Brasil e analisa-se, com base num referencial teórico da cadeia produtiva têxtil, a empresa. São feitas, algumas considerações teóricas sobre a inter-relação da inovação tecnológica com o conhecimento e apresentada uma visão geral tanto do desenvolvimento tecnológico do setor como do o cenário atual e melhoramentos dos seus processos produtivos. Por fim são descritas algumas razões e necessidades que levaram as empresas a se modernizarem utilizando a inovação tecnológica para melhorar a sua produtividade e qualidade dos seus sistemas de produção. 


\section{A CADEIA PRODUTIVA TÊXTIL NO MUNDO}

O setor têxtil é um dos segmentos de maior tradição dentro do segmento industrial, contando com uma posição de destaque na economia dos países mais desenvolvidos e carrochefe do desenvolvimento de muitos dos chamados países emergentes, que devem à sua indústria têxtil o papel de destaque que exercem, hoje, no comércio mundial de manufaturas. No Brasil, a sua importância não é menor, tendo desempenhado um papel de grande relevância no processo de desenvolvimento econômico e social do País.

Atualmente, pode-se verificar que o mercado têxtil mundial vem registrando uma significativa expansão, tanto no que se refere aos montantes produzidos, quanto ao comércio entre os grandes países produtores e consumidores. Isto tem sido possibilitado pela expansão do número de consumidores em todo o mundo, tanto pelo aumento da renda em alguns países mais desenvolvidos quanto pela abertura dos mercados ao comércio internacional. A partir de 2005, com o término do sistema de quotas para exportação de têxteis, é provável que o comércio mundial possa apresentar uma expansão ainda maior. Outros fatores importantes neste crescimento devem ser considerados, como o uso de novas matérias-primas e processos de acabamento, possibilitando maior uso de fibras artificiais e sintéticas, que, dentre outras vantagens, têm sua produção livre de problemas relativos a safras e climas. Seu consumo supera o de fibras naturais, tendo representado mais de $57 \%$ do total consumido em 2000 , (TEXTILIA, 2002).

Definindo-se a cadeia produtiva como o conjunto de componentes interativos, incluindo os sistemas produtivos, fornecedores de insumos e serviços, industriais de processamento e transformação, agentes de distribuição e comercialização, além de 
consumidores finais (CASTRO, 2000), apresenta-se a Figura 1 onde são mostradas a estrutura da cadeia produtiva têxtil e confecção.

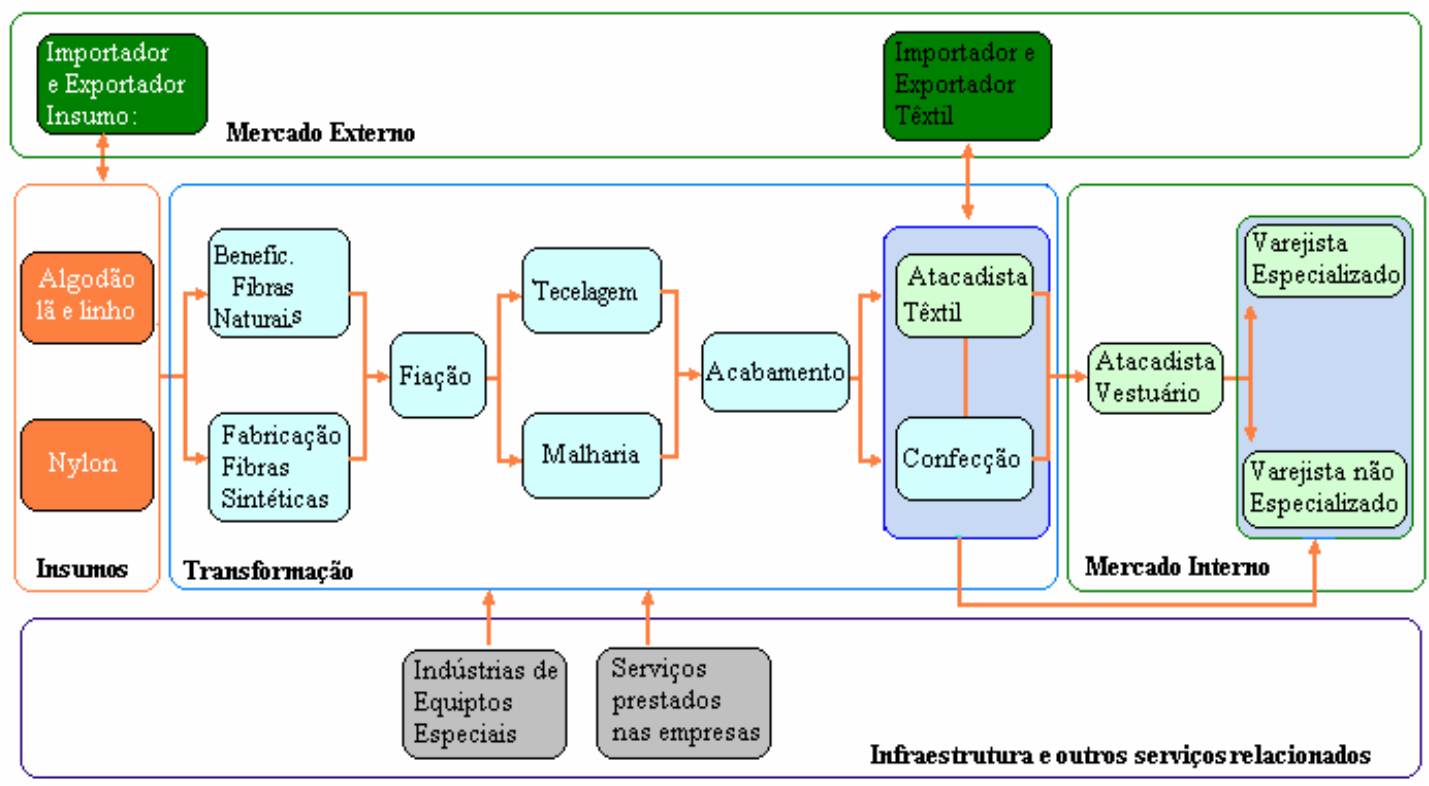

De acordo com a Figura 1, verifica-se que a cadeia têxtil é constituída dos segmentos de fiação, tecelagem e acabamento de fios e tecidos. Observa-se a interação entre os segmentos fornecedores a montante (equipamentos, produtos químicos, fibras e filamentos), e os produtores de manufaturas (fios, tecidos, malhas), e bens acabados a jusante (confeccionados e têxteis). As fibras têxteis são convertidas em fios através da fiação. Fibras de tipos diferentes podem ser fiadas conjuntamente, como por exemplo poliéster e algodão, ou lã e náilon. Os fios dão origem aos tecidos, através da tecelagem. Processos têxteis de acabamentos são então aplicados para conferir ao tecido propriedades particulares. Alguns destes processos, como o tingimento, podem ser aplicados nas fibras cruas, nos fios ou nos artigos acabados.

Observa-se também, que o segmento de tecelagem subdivide-se em: Tecelagem Plana e Malharia, onde cada um destes segmentos pode oferecer ao mercado um produto acabado e 
pode estar desconectado dos demais. A descontinuidade do processo produtivo é uma característica marcante da indústria têxtil. Embora os segmentos ou etapas do processo se interliguem pelas características técnicas do produto a ser obtido, e neste caso, o tecido a ser obtido determina o tipo de fibra, as especificações do fio e as características do acabamento, essas etapas não precisam, necessariamente, serem todas internalizadas pelas empresas. É comum a especialização em apenas um ou dois segmentos, o que torna as relações clientefornecedor especialmente relevantes em toda a cadeia produtiva.

\subsection{A Cadeia Produtiva Têxtil no Brasil - Histórico}

A industrialização no Brasil teve seu início com a indústria têxtil. No período colonial que se estende do século VI a meados do século XIX, a característica fundamental é a insipiência da indústria têxtil, além de sua descontinuidade. Nas décadas seguintes, houve uma aceleração do processo de industrialização e, às vésperas da I Guerra Mundial, o Brasil tinha 200 fábricas, e pode ser considerada como fator decisivo na consolidação da indústria têxtil brasileira, pois a limitação da capacidade do País de importar propiciou a oportunidade de crescimento da produção interna no vácuo deixado pelo não-suprimento externo de tecidos.

Esse processo foi aprofundado pela eclosão da II Guerra Mundial no século XX, período em que ocorreram realmente excepcionais alterações na estrutura industrial brasileira. Como os fornecedores tradicionais do Brasil estavam envolvidos no conflito, abriu-se a possibilidade de o mercado ser suprido por meio do incremento da produção interna, com o surgimento de muitas fábricas em praticamente todos os setores da atividade manufatureira. No ramo têxtil, as fábricas se ampliaram, passando a operar com mais de um turno de trabalho e produzindo mais para atender o mercado interno e, ainda, exportando para mercados importantes, principalmente da Europa e dos Estados Unidos. Todavia, terminado o conflito mundial, novamente o setor retornou à situação anterior. Com a normalização paulatina do 
mercado internacional, o país perdeu os clientes externos e as exportações caíram a níveis insignificantes. Os investimentos foram travados e o obsoletismo do equipamento em uso ficou patente.

Até a década de 80 , a indústria têxtil brasileira era detentora de um mercado interno cativo e em expansão e fechado às importações tanto de produtos acabados quanto de insumos e equipamentos. Toda a produção era consumida nacionalmente, sem concorrência de produtos importados. Como conseqüência não havia estímulo para realizar os investimentos necessários ao acompanhamento do processo de modernização que ocorria em outros países, o que contribuiu para que houvesse um decréscimo nos investimentos referentes à atualização e desenvolvimento do sistema da cadeia produtiva.

A partir dos anos 90, com a abertura do mercado local à concorrência internacional e, mais tarde, com a estabilização da moeda brasileira em 1994 com o Plano Real, o setor têxtil viu ser modificado por completo o cenário econômico que o havia levado a instalar-se e a crescer no País. Exposta de forma abrupta a um novo padrão de concorrência, teve de empreender um árduo esforço para se reposicionar e voltar a ser competitivo, só que, desta vez, em termos globais. Neste período houve o fechamento de muitas empresas que obrigou o setor a investir fortemente na sua modernização para reduzir custos e poder competir com os produtos importados.

Os países asiáticos, que se modernizaram rapidamente, apareceram junto com os Estados Unidos, entre os maiores produtores e exportadores mundiais neste segmento, representando a grande ameaça para a indústria têxtil brasileira, pois passaram a concorrer em nosso próprio mercado. 


\subsection{Panorama Atual da Indústria Têxtil no Brasil}

O setor têxtil nacional é composto por cerca de 3.800 empresas, todas de capital privado, representando um dos segmentos de grande importância para o setor manufatureiro. Segundo dados do Gherzi (1998), as vendas totais da indústria têxtil e de confecção foram de US\$ 19,6 bilhões em 1999, correspondendo a 3,8\% da produção industrial brasileira. Em relação à produtividade, 1,4 milhões de toneladas de matéria-prima são processadas na cadeia têxtil brasileira, com consumo de 8,9 kg, acima da média mundial de 7,6 kg.

A indústria têxtil brasileira é caracterizada pela heterogeneidade tecnológica e gerencial. Convivem, em um mesmo segmento de mercado:

- Empresas modernas, com padrão tecnológico e estratégias semelhantes às empresas de melhor desempenho mundial;

- Empresas parcialmente modernizadas, com equipamentos atualizados em etapas estratégicas ou mesmo com maquinário antigo, mas dispondo de rigoroso controle de qualidade e capacitação em design;

- Um grande número de empresas que têm padrões tecnológicos e gerenciais ultrapassados.

Por outro lado verifica-se que devido às inovações tecnológicas no parque fabril têxtil, houve um importante impacto na força de trabalho, exigindo maior nível de qualificação. A aquisição de novos equipamentos para as diversas fases do sistema produtivo, gerou uma demanda de treinamento especializado dos empregados em diversas etapas da cadeia produtiva, mostrando ser um importante fator determinante para a melhoria da competitividade. 


\section{CONSIDERAÇÕES TEÓRICAS SOBRE A INOVAÇÃO TECNOLÓGICA E OS PROCESSOS PRODUTIVOS DA INDÚSTRIA TÊXTIL}

Atualmente, um ponto muito discutido e considerado fator crítico para que as indústrias cresçam e desenvolvam é a questão da inovação tecnológica. Existindo as competências necessárias para alimentar uma cadeia produtiva baseada em tecnologia, possibilita-se o desenvolvimento regional. Os trabalhos de Melo, (2001, 1988), o de Melo, (2003), Sicsú (2001) e Ferraz (1998), analisam a relação entre planejamento e o desenvolvimento econômico regional com a inovação tecnológica.

As inovações tecnológicas podem ser divididas em: Incrementais e Radicais. As incrementais ocorrem paulatinamente, sendo resultado não só de pesquisa e desenvolvimento, mas de respostas às melhorias requisitadas por engenheiros e usuários. As radicais por sua vez ocorrem descontinuamente, com impacto, uma vez que podem gerar novos produtos e mercados. Observa-se que com as várias necessidades que precisavam ser satisfeitas, geradas pelos diferentes focos de pesquisas, foram desenvolvidas nas empresas diferentes formas de se conduzir a inovação tecnológica, surgindo vários conceitos. No setor têxtil, as inovações concentraram-se mais nos segmentos industriais de bens de capital e indústria química.

A concepção inovação tecnológica com conhecimento lançada em 2002 por DE MEYER et al., (DE MEYER Armand; DUTTA Soumittri; SRIVAHTAVA Sandeep. apud VELLOSO, 2005), parte da análise do que tem acontecido no campo das novas tecnologias onde afirma que: (VELLOSO, 2005, p. 6-7).

A Inovação vai ser um imperativo para a sobrevivência, e não apenas para o crescimento. A Inovação vai ser rotina, e a quantidade da Inovação não irá contar menos que a qualidade. Os autores dão ênfase à real natureza da Inovação, e a sua ligação com o Conhecimento: Embora a Inovação às vezes seja o resultado de serendipity (acidentalidade, casualidade), na maioria dos casos ela é o resultado de um foco sistemático na acumulação, melhoria e aplicação do Conhecimento. O Conhecimento se situa na raiz da Inovação e a Inovação cria Conhecimento novo. Em realidade, existe uma forte relação de sinergia entre Conhecimento e Inovação. 
Ressalta-se que a gestão do conhecimento está intimamente interligada com as pessoas que trabalham nas organizações (SMITH; MCLAUGHLIN, 2004). É o conjunto total incluindo cognição e habilidades que os indivíduos utilizam para resolver problemas. Ele inclui tanto a teoria quanto a prática, as regras do dia-a-dia e as instruções sobre como agir. O conhecimento baseia-se em dados e informações, mas ao contrário deles está sempre ligados a pessoas. Ele é construído por indivíduos e representa suas crenças sobre relacionamentos causais (PROBST et al., 2002).

Velloso (2005, p. 26) afirma que:.

$\mathrm{Na}$ Economia do Conhecimento, ficam esmaecidas as fronteiras entre crescimento econômico, desenvolvimento social, capital humano, cultura e valores humanistas (convergência para uma visão globalizante do desenvolvimento). Só há verdadeiro desenvolvimento com grande geração de empregos (bons empregos), inclusive para reduzir a um mínimo a informalidade. Importância de um modelo como a Economia do Conhecimento para a auto-estima nacional.

Park e Lee (2005) da Sun-Moon University and Kyeongnam Development Institute, Korea, também apresentam o seu modelo de desenvolvimento regional tendo como fator principal a economia baseada no conhecimento.

Os impactos da abertura da economia foram diferenciados segundo o porte e o estágio de utilização tecnológica das empresas do setor. As grandes empresas exportadoras, já vinham reduzindo seus custos industriais e aumentando a sua produtividade no período anterior à abertura, principalmente através da implantação de novas técnicas organizacionais. O mesmo não ocorreu com a maioria das médias e pequenas empresas em que algumas não passaram por qualquer processo de modernização nos últimos anos, tendo sido o ajuste nessas circunstâncias muito mais penoso (RODRIGUES, 1996). 
As inovações no processo produtivo têxtil nas últimas décadas foram intensas, principalmente nos bens de capital e no desenvolvimento de novas fibras. As operações ficaram mais velozes com a maior utilização de fibras químicas, e melhoria das fibras naturais.

\subsection{A Inovação e o Conhecimento na Cadeia Produtiva Têxtil}

O desenvolvimento e avanço tecnológico da indústria têxtil abrangem outros segmentos como o agroindustrial, químico e metal-mecânico. Merece destaque o desenvolvimento tecnológico no cultivo e produção de fibras de "Algodão Colorido" na Paraíba, que não necessitam de tingimento. Na cadeia produtiva têxtil em relação a processos de produção ou produto, o desenvolvimento tecnológico é incremental, com pouquíssima inovação radical. Os avanços concentram-se mais no desenvolvimento de novas fibras e máquinas mais velozes. As tecnologias utilizadas nos sub-setores de fiação são incorporadas em máquinas e equipamentos. Observa-se a dependência entre o setor têxtil e desenvolvimentos dos bens de capital quando se faz a verificação do desenvolvimento tecnológico de indústrias ao longo do tempo. Nota-se também que o desenvolvimento tecnológico foi conseqüência das modificações químicas nas fibras existentes, criando fibras novas, que podem substituir o algodão.

A utilização da tecnologia para aumento da produtividade das máquinas pode ser observada em alguns indicadores de produção do sub-setor fiação. Houve aumento na velocidade das cardas, o que gerou aumento na produção de filatório. A criação do sistema Open-End, eliminando etapas no processo de produção, foi uma das grandes inovações. $\mathrm{O}$ setor está sendo mais intensivo em capital que em mão-de-obra. 


\subsection{Necessidades Tecnológicas no Cenário Atual}

A competitividade do cenário atual do setor têxtil pode ser caracterizada pela capacidade das empresas em produzir e entregar artigos diferenciados e cada vez mais complexos, em um menor tempo possível. Não só o tempo é uma variável importante, mas também os custos e a integração entre todos os setores da cadeia produtiva.

De acordo com um estudo do Lloyds Bank (apud MIRANDA, 1998), o setor têxtil e de vestuário tem, de forma geral, um histórico complicado no Brasil: Defasagem tecnológica, grande número de empresas familiares e baixa preocupação com produtividade e profissionalização. Estes tópicos adicionados aos efeitos da abertura de mercado, à globalização no setor têxtil e ao modelo econômico vigente a partir de 1994, afetaram de forma bastante acentuada a indústria têxtil brasileira.

Para que o setor seja mais competitivo e produtivo, em um mercado cada vez mais global, investimentos maciços em máquinas e equipamentos têm sido feitos, para compensar uma defasagem tecnológica que impedia o avanço da competitividade da indústria têxtil no mercado externo. Dados do setor apontam que as máquinas em operação no país têm, em média, 16 anos de uso, quando deveriam ser trocadas a cada cinco anos. Os equipamentos novos e de última geração representam um percentual baixo na linha produtiva.

\section{ANÁLISE E ESTUDO DE CASO}

\subsection{Metodologia Utilizada}

Os procedimentos metodológicos utilizados neste trabalho foram desenvolvidos através de um estudo de caso, a partir da observação de uma das empresas do segmento de fiação do setor têxtil. A partir da avaliação buscou-se fazer um estudo comparativo da realidade observada no segmento de fiação da empresa alvo com a teoria estudada. 
A empresa estudada do setor de fiação se localiza em Campina Grande-PB e possui grande representatividade nacional. A principal ferramenta utilizada para análise qualitativa e quantitativa foi um questionário estruturado para coleta dos dados junto aos gerentes de processo e produção da empresa, bem como uma adequada bibliografia acadêmica para um maior embasamento teórico.

\subsection{Inovação Tecnológica}

A empresa têxtil, em análise, opera há quase uma década no setor de fiação. Conta com duas unidades e o seu quadro de funcionários é em torno de 1.000 pessoas, atuando nas áreas administrativas e de produção. A sua receita em participação das exportações, nos nove primeiros meses do ano de 2003 foi em torno de $60 \%$. A empresa se encontra num processo de expansão das exportações, por isso sua preocupação com a produção de fios com um padrão de qualidade internacional.

As unidades de Campina Grande produzem apenas os fios, que posteriormente serão utilizados como matérias-primas pelas outras unidades do grupo da cadeia produtiva, situadas em vários Estados do Brasil (RN, MG e SC). A empresa se encontra num contínuo processo de inovação tecnológica, com a aquisição das mais modernas máquinas de fiação existentes no mundo. Hoje, devido seu grau de desenvolvimento e organização, a empresa é um referencial mundial da indústria têxtil. No que tange a percepção dos cenários interno e externo, a posição tecnológica da empresa é muito desenvolvida, tendo inclusive como estratégias de negócios o investimento em capacitação de recursos humanos, expansão da capacidade produtiva e atuação em novos mercados.

O aumento da concorrência no setor, fez com que a empresa buscasse formas para aumentar sua competitividade, como por exemplo, adoção de sistemas e máquinas automatizadas. A automação no setor têxtil busca a racionalização dos processos através da 
economia de insumos (vapor d'água, água industrial, energia elétrica etc), a padronização dos processos, devido à diminuição dos erros operacionais causados por sistemas de controle manuais, aumento da possibilidade de se diversificar a produção, diminuição do prazo de entrega, melhora da qualidade do produto e preço justo.

A automação do setor está baseada em microprocessadores locais e computadores gerenciais centrais. Dependendo do tipo de microprocessador e nível de automação, os processos podem ser completamente controlados e gerenciados.

No caso particular da empresa estudada, verificou-se um elevado grau de automação e uma infra-estrutura condizente com a realidade. As matérias-primas são de boa qualidade, assim como as utilidades (vapor d'água e água industrial) passam por todo um processo de osmose, garantindo a qualidade; todas as tubulações estão em ótimo estado e o pessoal para operar ou gerenciar os sistemas têxteis automatizados são bem treinados sendo qualificados para isso.

\subsection{A Logística Interna e o Aumento da Produtividade}

A logística interna e o manuseio de materiais são áreas onde existe um grande desenvolvimento de sistemas automatizados. Além de aumentar a velocidade de transporte e organizar o fluxo de materiais, estes sistemas fornecem maior segurança aos operadores.

No segmento de fiação, o transporte e manuseio de matéria-prima e produtos semielaborados eram realizados em geral de forma manual e inadequada, prejudicando a qualidade dos produtos de toda a cadeia a jusante. Os filatórios com idade média de 20 anos, com produtividade média de $15 \mathrm{Kg} / \mathrm{h}$, ao invés de $60 \mathrm{Kg} / \mathrm{h}$ dos equipamentos mais modernos.

Neste sub-setor, todas as formas de melhoria com inovação tecnológica dos sistemas de logística interna e transporte de materiais estão sendo implementados nas empresas, desde 
a sala de abertura até a armazenagem dos fios. Os principais desenvolvimentos estão nas áreas de carregamento, descarregamento e alimentação de máquinas, e transporte de uma máquina para a subseqüente. Como exemplo podem-se citar os dispositivos para transporte de bobinas, através de um veículo guiado automaticamente (VGA).

Outro sistema que pode ser mencionado é o transporte de latas com fitas de algodão e poliéster para os Open-End. Anteriormente este mesmo transporte era feito manualmente com carrinhos que levavam para cada grupo de máquina 8 latas num tempo de 13 minutos, hoje, já se observa dentro dos corredores fabris carrinhos movidos à bateria, que transportam 8 latas em um tempo de 8 minutos. O que se verifica é não somente o ganho de tempo, mas também um aumento da produtividade do colaborador desta função, pois se no início de seu turno de trabalho ele conseguia carregar 8 latas em 13 minutos, no final ele mal podia transportar 4 em um maior espaço de tempo, ratificando mais uma vez o ganho de produtividade em sistemas automatizados.

\subsection{Desenvolvimento de Novos Processos}

Para o desenvolvimento de novos processos, a integração entre os construtores de máquinas, fornecedores de produtos e de componentes eletro-eletrônicos se torna condição fundamental. No sub-setor de fiação, os desenvolvimentos se concentram no aumento da velocidade de produção, bem como a adição de sistemas que controlam a qualidade do produto durante as etapas de produção. Atualmente, um dos grandes desenvolvimentos neste sub-setor é o processo de fiação por compactação. Este processo está baseado na compressão das fibras estiradas, por elementos mecânicos, com aspiração. Logo após, a torção é feita. Este processo permite uma redução da torção e uma melhor estiragem. Como resultado final deste processo, tem-se um fio de maior resistência, com um menor número de pontos fracos e uma 
baixa pilosidade. Os tecidos planos e de malha produzidos com este fio, possuem uma estrutura superficial mais clara e brilhosa (EGBERS, 1999).

Todos os sistemas criados para otimizar os processos, devem levar em consideração a qualidade do artigo produzido. Com a grande variedade de artigos têxteis lançados no mercado, as máquinas e sistemas devem ser flexíveis. Isto é, elas devem beneficiar, desde artigos simples, composição simples, de alta gramatura (tecidos pesados) até artigos delicados com uma composição de fibras e armações variadas.

\section{RESULTADOS E CONCLUSÕES}

Nos últimos dois anos a empresa vem renovando o seu parque fabril, investindo em inovação tecnológica com máquinas mais modernas, que oferecem uma maior produtividade. Um exemplo nítido deste avanço tecnológico aliado à alta capacidade produtiva, é que a empresa em análise possui uma produtividade que é considerada uma das maiores da indústria têxtil do mundo em termos de números de máquinas de fiação por metro quadrado.

O investimento em inovação tecnológica nos processos de logística interna gerou um aumento da produtividade no transporte de latas com fitas de algodão e poliéster para os Open-End.. Ressalta-se também os dispositivos para transporte de bobinas, através de um veículo guiado automaticamente (VGA).

A introdução da inovação nos sistemas e máquinas automatizadas contribuiu muito para a melhoria dos processos de produção. A automação do setor está baseado em microprocessadores locais e computadores gerenciais centrais. Dependendo do tipo de microprocessador e nível de automação, os processos podem ser completamente controlados e gerenciados. Verificaram-se as seguintes melhorias: 
a) Racionalização dos processos através da economia de insumos (vapor d'água, água industrial, energia elétrica etc).

b) Padronização dos processos e conseqüentemente diminuição dos erros operacionais causados por sistemas de controle manuais.

As inovações tecnológicas adquiridas com as novas aquisições melhoraram não só a produtividade, mas também a qualidade dos fios produzidos, o que se tornou um diferencial nos artigos fabricados. Nos últimos dois anos houve uma redução de $75 \%$ do número de reclamações de fios "barrados", ou seja, fios que quando tingidos dão uma variação de cor.

O parque fabril da empresa conta com um número significativo de máquinas OpenEnd responsáveis pela fabricação de diversos tipos de fio e variedade de espessura. Essa maior variedade foi possível graças ao aumento da capacidade de todo o parque fabril, com a aquisição de máquinas mais potentes, que possuem uma maior velocidade de processamento das fibras, possibilitando o sistema atender um maior número de pedidos de tipos diferentes dos clientes.

Quanto à melhoria e desenvolvimento de novos processos, a integração entre os fabricantes de máquinas, fornecedores de produtos e de componentes eletro-eletrônicos se torna condição fundamental. Um dos grandes desenvolvimentos neste sub-setor é o processo de fiação por compactação, onde se obtém um fio de maior resistência, com um menor número de pontos fracos e uma baixa pilosidade. Os tecidos planos e de malha produzidos com este fio, possuem uma estrutura superficial mais clara e brilhosa, conseqüentemente de melhor qualidade. 


\section{REFERÊNCIAS}

CASTRO, Antônio M. de Castro. Análise da Competitividade de Cadeias Produtivas, EMBRAPA, In: Workshop sobre Cadeias Produtivas e Extensão Rural na Amazônia, Manaus, Agosto 2000.

EGBERS, G. ITMA 99: Uma Luz al final Del Túnel. International Textile Bulletin, v .4, p. 11-15, 1999.

FERRAZ, João Carlos; KUPFER, David; HAGUENAUER, Lia. Made in Brazil: Desafios Competitivos para a Indústria. Rio de Janeiro: Campus, 1998.

GHERZI. Melhoria na Competitividade da Indústria Brasileira Têxtil e de Vestuário. Resumo executivo: Gherzi, São Paulo, Junho 1998.

JÚNIOR, E. B.; HEMAIS, C. A. Cenário do Setor Têxtil durante a Década de 90 - Parte II. Revista Têxtil, v. 4, p. $24-36,2000$.

MELO, Lúcia P. SUDENE A Função Ciência, Tecnologia e Inovação (CT\&I) na Nova Agenda de Desenvolvimento para o Nordeste (Diagnóstico e Propostas para a Ação da nova SUDENE), Brasília, Jun 2003.

MELO, Maria Ângela C. Planejamento em Tempo de Incerteza: um paradoxo? RECITEC Fundação Joaquim Nabuco - FUNDAJ, Recife, v. 5, p. 171-186, 2001.

A Abordagem da Escolha Estratégica: Operacionalização do Planejamento Adaptativo. In: VIII ENCONTRO NACIONAL DE ENGENHARIA DE PRODUÇÃO- 8 ENEGEP, São Carlos,1988.

MIRANDA. J. M. S. Perfil da Indústria Têxtil e de Vestuário Brasileira com o Novo Cenário Macroeconômico Mundial. Rio de Janeiro SENAI-CETIQT, v. 1, p. 35-45, 1998. 
PAVITT. K; BESSANT J.; TIDD. J. Managing Innovation - Integrating Technological, Market and Organizational Change. London: John Wiley \& Sons, 1984, p. 25-33.

PARK, Soo Young; LEE, Woobae. Regional Innovation System Built By Local Agencies: An Alternative Model of Regional Development, Sun-Moon University and Kyeongnam Development Institute. Disponível em: <http://econgeog.misc.hit-u.ac.jp/icgg/intl_mtgs/SYPark.pdf> Acesso em: Jun 2005.

PIO. M. J.; JÚNIOR, E. B.; ANTUNES. A.; HEMAIS. C. A. O Impacto das Inovações tecnológicas na cadeia têxtil produtiva. In: XIX CONGRESSO NACIONAL DE TECNOLOGIA TÊXTIL-CNTT, Ceará, Set 2000.

PROBST, Gilbert et al. Gestão do Conhecimento: Os Elementos Construtivos do Sucesso. Porto Alegre: Bookman, 2002.

RODRIGUES, L. H. Tecnologia de Tecelagem. Rio de Janeiro: CETIQT, 1996.

SEBRAE. Disponível em: <www.geo.sebrae.com.br/geodw/cadeia2.as> Acesso em : Fev 2004.

SICSÚ, Abraham B.; DIAS, Adriano B. Condicionantes das Políticas de Gestão do Conhecimento: Novo Enfoque em Busca da Competitividade. Recife: MPA SUDENE. 2001.

SICSÚ, Abraham B. Evolução do Paradigma Tecnológico Industrial e Novas Formas de Apoio às Organizações Industriais. Recife: MPA SUDENE. 2001.

SICSÚ, Abraham B.; COUTINHO, L.; LIMA, J. P; HULAK, Maria H. A Inserção Competitiva do Nordeste. Recife: MPA SUDENE. 2001.

SICSÚ, Abraham B. Inovação Tecnológica e Investimentos, Recife: MPA SUDENE. 2001. 
SMITH, Peter; MCLAUGHLIN, Moira. Knowledge Management: People Are Important!.

Journal of Knowledge Management Practice, v. 5, Jan 2004.

SUDENE. Bases para a Recriação da SUDENE - Grupo de Trabalho InstitucionalBrasília: Ministério da Integração Nacional, Jun 2003.

TEXTILIA. A Indústria Têxtil no Brasil e no Mundo. 30/10/2002. Revista Textilia Net,

Disponível em:

<http://www.textilia.net/index.asp?PLC_page=4_1_1_1\&PLC_map_001_c=050104\&PLC_c ng_ukey=STAR_STAR_0ST0Y8M3Z\&PLI_page=2 >Acesso em: Jun 2005.

VELLOSO, João Paulo Reis. O Brasil e a Economia do Conhecimento - o Modelo do Tripé e o Ambiente Institucional, In: XVII FÓRUM NACIONAL CHINA E ÍNDIA COMO DESAFIO E EXEMPLO E A REAÇÃO DO BRASIL PARA CIMA, Rio de Janeiro: INAE, Maio 2005.

VELloso, João Paulo Reis. Apresentação da Palestra: O Brasil e a Economia do Conhecimento - o Modelo do Tripé e o Ambiente Institucional, In: XVII FÓRUM NACIONAL CHINA E ÍNDIA COMO DESAFIO E EXEMPLO E A REAÇÃO DO BRASIL... PARA CIMA. Disponível em:

<www.forumnacional.org.br/publi/ep/ep0108.pdf > Acesso em: Jun 2005.

Artigo recebido 30/06/2006 em e publicado em 21/08/2007. 